\title{
La República Popular China en el África subsahariana. Notas de una relación geoeconómica contemporánea*
}

DOI: $10.32870 /$ mycp.v14i40.360

Martín M. Checa-Artasu ${ }^{1}$

\section{Resumen}

I omando como punto de partida el concepto de la geoeconomía, se analiza la interacción de la República Popular China con el conjunto de países del África subsahariana. Esta interacción es objeto de debate y análisis, dadas las expectativas que genera y los cambios que plantea para la región.

Palabras clave: geoeconomía, África, China, recursos naturales, cooperación.

\section{Abstract}

Geo-economics concept is a starting point to examine the economic interaction between the Popular Republic of China and Sub-Saharan African countries on the whole. This interaction is the subject of debate and analysis since expectations that it generates and changes that it raises to the region.

Keywords: geo-economics, Africa, China, natural resources, cooperation.

* Artículo recibido el 11 de agosto de 2010 y dictaminado el 28 de octubre de 2010.

1. Doctor en Geografía Humana por la Universidad de Barcelona, España. Profesor-investigador del Departamento de Sociología, Universidad Autónoma Metropolitana, campus Iztapalapa; miembro del SNI, nivel 1. ORCID http://orcid.org/0000-0002-6372-2938 Correo electrónico: mcheca@sct.ictnet.es 


\section{Un apunte teórico a modo de introducción ${ }^{2}$}

En 1999, el economista y politólogo francés Pascal Lorot ponía en juego el término geoeconomía para conceptualizar y explicitar cómo las economías de los países se relacionan y/o afectan entre sí. ${ }^{3}$ La geoeconomía, según la propia definición de Lorot, (2000) es:

El análisis de las estrategias de orden económico, especialmente comercial, decididas por los estados en el marco de las políticas encaminadas a proteger su economía nacional o sectores bien definidos de la misma, para adquirir el dominio de tecnologías clave y/o conquistar segmentos del mercado mundial relativos a la producción y a la comercialización de un producto o una gama de productos sensibles, que confiere a su poseedor un elemento de poder y de presencia internacional, que ayuda a reforzar su potencial económico y social.

De esa manera Lorot clarificaba las tesis en cuanto a la geoeconomía expuestas por el politólogo estadounidense Edward Luttwak, quien advertía, ya en 1990, de un cambio en la arquitectura de las relaciones internacionales. Luttwak señalaba que el papel de lo militar y sus alianzas había tocado su fin tras la caída del Muro de Berlín y que el nuevo paradigma vendría marcado por el papel de la economía, donde la difusión y control de la tecnología, el papel de la inversión, la búsqueda, desarrollo y establecimiento de nuevos mercados llevaría parejo un mayor dominio de la escena mundial e incluso sería determinante para el posicionamiento como potencia hegemónica. La economía envolvía a la geopolítica para convertirse en geoeconomía. Este politólogo, asimismo, señala cuáles son las principales herramientas de la geoeconomía (Luttwak, 1993: 399 y 400):

2. Una versión preliminar de este trabajo fue presentada en el Seminario Anual de Investigación 2008, Centro Universitario de Estudios e Investigaciones sobre la Cuenca del Pacífico, Facultad de Economía, Universidad de Colima, 23-24 de octubre de 2008.

3. Pascal Lorot es miembro de la Comisión para la Regulación Energética del gobierno francés desde 2003. Ha sido director de estudios económicos del grupo petrolero Total (1995-2002). Ha sido consejero de la Presidencia del Banco Europeo de Reconstrucción y Desarrollo (BERD) e investigador del Institut français des relations internationales (IFRI). Asimismo es fundador de la revista trimestral Géoéconomie y director de éditions Choiseul, editora entre otras revistas de Monde Chinois, Politique Américaine, Problèmes d'Amérique latine, Nordiques y MaghrebMachrek. 
En geoeconomía, como en la guerra, las armas ofensivas dominan. Entre ellas, la $\mathrm{I}+\mathrm{D}$, ayudada por los estados con el dinero de los contribuyentes, tiene una importancia capital. De forma similar a la guerra, la artillería conquista por su potencia de fuego el terreno que ocupara la infantería, el I+D puede conquistar el terreno industrial de mañana permitiendo asegurar una superioridad tecnológica decisiva. La artillería de la I+D sostenida por el Estado es crucial, pero es necesario, además, prestar asistencia a la infantería, es decir al sector productivo. La última ofensiva es la de las finanzas. Si la artillería de I+D no llega a conquistar los mercados, si las subvenciones de funcionamiento otorgadas de una u otra manera se muestran insuficientes, se puede ayudar a exportar ofreciendo préstamos a tipos de interés inferiores al mercado.

Dichas herramientas, desarrolladas desde el sistema capitalista imperante e incentivado por los procesos afines a la globalización, han determinado el papel relevante de la geoeconomía en el marco de las relaciones internacionales, haciendo así válidos en gran medida los presupuestos de Luttwak.

Esto ha implicado un cambio cualitativo en la forma de actuar de los estados y de otros sujetos que han ido apareciendo en este contexto: las empresas multinacionales, las áreas económicas regionales integradas, las instituciones económicas internacionales, etc.; todos ellos son, a la vez, agentes y sujetos de estudio de la geoeconomía.

Un tercer elemento que analiza la geoeconomía es cómo el marco económico se interrelaciona con un espacio cada vez más poroso, menos físico, de fronteras diluidas y flujos informacionales. En esa interrelación, las acciones económicas devienen esenciales, pues llegan a modificar el mismo espacio y hay que tenerlas en cuenta para un cabal entendimiento de las realidades que se han venido generando desde esa perspectiva. Conviene decir que esas interrelaciones espacializadas unas veces son de cooperación y otras conflictivas. Se trata de un cuarto elemento de análisis de la geoeconomía, ya que esta subdisciplina también se preocuparía de analizar las acciones de competencia y de cooperación, no sólo de los estados sino también de empresas multinacionales, de las áreas económicas y de las organizaciones económicas internacionales en el espacio mundo (Ávila y Díaz Mier, 2004).

Así pues, en consonancia con este concepto teórico, se puede analizar la interacción de la República Popular China con los diversos países del África subsahariana. Los presupuestos emanados de la geoeconomía pueden explicar el creciente y activo papel del gigante asiático en este ámbito regional. Una comprensión que de forma sucinta y unilateral — por el momento nos centraremos 
en la relación de la República Popular China con los países de la región- trataremos en este trabajo. El mismo es un primer avance de una investigación en curso más amplia que pretende comprender la relación desde las dos partes. Conviene precisar que hemos centrado nuestro análisis en la entidad regional denominada África subsahariana por tener ésta unas características concretas respecto a su relación con China, excluyendo así tanto el norte de África o la cuenca africana del Mediterráneo, como también la República de Sudáfrica.

\section{África subsahariana: algunas notas geográficas}

El África subsahariana es una región que, más allá del número de estados que aglutina (48) y de sus diversidades medioambientales evidentes, presenta una serie de características comunes de orden económico y político, como son: un crecimiento demográfico expansivo desde la década de los sesenta del siglo Xx que ha activado un éxodo rural hacia las ciudades, provocando la hipertrofia de lo urbano, en cuanto a la falta de condiciones de éste y de nula vertebración entre las distintas realidades urbanas. Asimismo, se detecta una bipolarización del sector agrario, con un importante porcentaje del sector centrado en la agricultura de subsistencia y con un creciente papel de la agricultura comercial. El escaso desarrollo tecnológico de la primera y la dependencia exportadora de la segunda impiden que el sector pueda alimentar a esa masa poblacional en crecimiento y cada vez más urbana, generando así continuas crisis alimentarías.

Además, la región presenta una baja actividad industrial, centrada en procesos extractivos como la minería, el petróleo o materias primas como el algodón, el caucho o la madera que apenas generan desarrollo, sustrato técnico y valor añadido en los países productores, por su carácter eminentemente exportador (Méndez, Molinero, 2002: 571-629). En términos de gobernanza, la región vive aún sumida en los efectos del neocolonialismo, donde las élites locales, incardinadas en el ejercicio del poder, permiten el control de las fuentes económicas por parte de empresas extranjeras, algunas originarias de las antiguas metrópolis, con el consentimiento y ánimo del mantener los hilos del poder a cualquier precio. Asimismo, asociado a ese mismo neocolonialismo, las potencias occidentales activaron el mecanismo de la ayuda externa como motor del desarrollo, resultando el mismo un sonoro fracaso, pues constriñó las propias economías ahogadas por los pagos de esa ayuda, formulada en préstamos, desactivó el ahorro interno y mantuvo una alta dependencia económica del exterior. 
Ahora bien, la misma dependencia exterior, combinada con los efectos de la globalización parece ser una de las posibles vías para un cambio de paradigma en el África subsahariana. La aparición de China, país con una alta demanda de recursos naturales para mantener su crecimiento económico y que vertebra esa política a las ventajas de la globalización, así parece indicarlo (Mills, 2008: 14-16).

El crecimiento económico chino, aunado a los mecanismos propios de la globalización obliga a China a participar activamente en la búsqueda de mercados poco desarrollados y limitados. Se trata de una participación que está produciendo sinergias y efectos detonantes en esos mercados, ya que los activa hacia transacciones y relaciones comerciales en muchos casos inéditas. Para China, la activación de esos mercados está íntimamente ligada a dos cuestiones. Por un lado, la búsqueda de materias primas para continuar su desarrollo económico y, por otro, el establecimiento de puntos de comercialización para su ingente producción industrial.

Esas dos cuestiones adquieren relevancia y explican la creciente y notoria relación económica de la República Popular China (RPC) con diversos países subsaharianos.

A su vez, para el África subsahariana la presencia de China representa un incremento, lento todavía, en sus ratios de exportación y sobre todo en sus flujos de inversión extranjera. Así, por ejemplo, la Economic Commission for Africa, dependiente de Naciones Unidas, cifraba que la inversión foránea se había incrementado en un 20\% en 2006 para África. Un incremento propiciado por el aumento global de las inversiones provenientes de los países emergentes asiáticos; 17\% de las inversiones extranjeras en 2005 eran de esa zona. China, en concreto en el año 2006 invirtió 1,610 millones de dólares, 32\% más que el año anterior en el conjunto de África, elevando el monto inversor a 7,600 millones de dólares (ECA, 2008: 31). Otros países con inversiones superiores a las chinas en el área son Malasia y la India. También destacan las realizadas por Corea del Sur y Singapur.

\section{El papel de China en el África subsahariana: posturas de un debate abierto}

La emergencia de China en el África subsahariana ha sido fulgurante comparativamente con el lento desarrollo de la cooperación y comercio con las potencias occidentales en la zona. En estos momentos China ya es el segun- 
do socio comercial de África, por detrás de Estados Unidos y por delante de Francia y Gran Bretaña (Hanson, 2008). Esa emergencia ha sido vista con ambivalencia, pues está repleta de promesas y de peligros. Por un lado, el gigante asiático invierte en infraestructura, algo que apenas habían hecho los países occidentales, generando ciertas sinergias en la creación de empleo y desarrollo. Igualmente, mediante la importación de productos desarrolla un mercado con mayores ofertas para los africanos. Por contra, la misma importación de productos chinos pudiera acabar con los débiles fabricantes africanos.

También la propia caracterización de la producción subsahariana promueve los procesos extractivos depredadores que generan poco valor añadido en la creación de una base de desarrollo económico e industrial. Asimismo, China muestra una alta despreocupación por las formas y modos de gobernanza de los dirigentes africanos, un elemento que se contrapone como cláusula negociadora en los tratos que hacen los países occidentales. Todas estas ambivalencias han generado un intenso debate y una serie de posicionamientos en el análisis de esa interacción entre el África subsahariana y China.

Las posiciones en ese análisis transitan entre aquellos que consideran que la República Popular China es una potencia neocolonial, que recupera y moderniza las estrategias usadas por otros en el pasado, en aras de una explotación y búsqueda sistemática de recursos naturales. Algunos autores incluso ya tildan la actuación china de imperialista (Manji y Marks, 2007; Marks, 2006; Niquet, 2007; Guerrero y Manji, 2008; Melber, 2007; Rocha, 2008; Van de Looy, 2006). Otros, especialmente autores chinos, ven en la actuación de China en África una posibilidad para incidir en el desarrollo de algunos países africanos, ligada a la doctrina del desarrollo pacífico que desde 2005 rige las relaciones internacionales chinas y las acciones derivadas de lo que se ha convenido en llamar el "Consenso de Pekín” (Yi, 2005: 91 y 92; Ramo, 2004; Rocha Pino; 2006: 712-714; Guo, 2006).

Otros, probablemente con un importante viraje hacía la cuantificación de los datos económicos de la relación, consideran que China ve en África un incipiente mercado donde colocar sus productos, entrando así en competencia con países que tradicionalmente exportaban mercancías a los mercados africanos, pero a su vez propiciando la vertebración de los mercados africanos (Alves, 2006, Goldstein, 2006; Zafar, 2007; Boardman, 2007; Kurlantzick, 2006). Una voz, en esa misma sintonía, pero que incide con bastante profundidad en el papel relevante que desempeña la ayuda, la asistencia técnica y la 
reducción de la deuda externa que los países africanos tenían con China, es el trabajo de Brautigah (2009). Esa misma cuestión de la deuda y de la ayuda que China concede a los países del continente africano ha sido debatida, planteando si la misma es esencialmente ayuda, o bien si es la estrategia para el acceso de las inversiones y por ende de los recursos naturales que interesan al gigante asiático (Keenan, 2009).

Otras voces, provenientes tanto de estudiosos del mundo africano como de autores que trabajan la problemática del respeto de los derechos humanos en China, alertan acerca de la falta de ética de la intervención económica de China, acusándola de un pragmatismo antiético, pues en aras de los intereses arriba aludidos, no duda en tener tratos con regímenes dictatoriales, corruptos y/o nada escrupulosos con los derechos humanos. Unas acusaciones que coinciden con las que desde algunos cenáculos se lanzan contra el propio régimen gobernante en la República Popular China. En algún caso se alerta siguiendo los presupuestos propios de la ecología política, de los efectos que la explotación de los recursos naturales por parte de empresas chinas pudiera tener en el medio ambiente de los países afectados (Manji y Marks, 2007; Qinglian, 2008; Taylor, 2008).

Sin omitir la certeza de algunas acusaciones e incluso reconociendo el pragmatismo en virtud del interés económico de esta relación, no se puede olvidar que otros países de forma más sistemática, con mayor trayectoria en su presencia africana y diversas transnacionales se rigen con los mismos presupuestos que los empresarios y gobierno chino, como recuerda Sautman (2006: 3-5). ${ }^{4}$

4. Se trata de políticas y acciones que incluso han inspirado novelas y películas de gran aceptación; cito por caso The Constant Gardener (2001) de John Le Carré, sobre la acción de las 
Son pocos, sin embargo, quienes alertan de las posibles consecuencias a medio y largo plazos de la dependencia de las exportaciones con el gigante asiático por parte de algunos países africanos. Consecuencias que pasan por la reproducción del fenómeno económico conocido como dutch disease (Rocha, 2008). Ese concepto económico, que pone en relación la disponibilidad de dotaciones de productos energéticos con el deterioro del sector de manufacturas, tomando el ejemplo acontecido en Holanda en la década de los sesenta, ya se ha registrado en algunos países africanos en el pasado reciente, como por ejemplo en la década de los noventa en Nigeria, y pudiera amenazar a países como Sudán, Guinea Ecuatorial e incluso Angola (Mkandawire y Soludo, 1999: 15 у 34).

Algunos analistas apuntan que pudiera ser ésta una relación vista por los dirigentes africanos como más comprensiva, pero sobre todo más redituable que la que ha realizado y realizan Estados Unidos y los países de la Unión Europea en la zona (Sautman, 2006). La misma, incluso, podría ser entendida como un nuevo paradigma en las relaciones sur-sur y un remedo ante la incomprensión occidental de los problemas de África (Gill y Reilly, 2007; Melber, 2005; Davies, 2007; Guijin, 2004).

\section{Marco de las relaciones entre China y el África subsahariana}

La relación África subsahariana-China promueve un marco de relaciones internacionales vinculadas a lo que se ha venido en llamar Consenso de Pekín, definido por Joshua Cooper Ramo en 2004 (Thompson, 2005; Braud, 2005). Esta teoría se basa en la voluntad de innovar en las relaciones internacionales, promovida por las nuevas hornadas de dirigentes chinos. Esa innovación tiene como base una fuerte creencia en la soberanía de los países, en el multilateralismo y en el deseo de acumular herramientas para la proyección de un poder asimétrico. Se trata de un planteamiento que tiene la intención de limitar el poder político y militar de Estados Unidos, así como plantear una alternativa a los postulados del Consenso de Washington y mantener un clima pacífico a nivel internacional que mantenga la prosperidad china (Ramo, 2004).

multinacionales farmacéuticas en Kenia, o la película Blood Diamonds (2006) dirigida por Robert Zewick, sobre la guerra en Sierra Leona y sus vinculaciones con las explotaciones de diamantes y que en su momento puso en alerta a la empresa sudafricana De Beers, principal distribuidor mundial de diamantes para joyería. 
Esa misma relación es coincidente con los presupuestos de la doctrina del desarrollo pacífico (heping fazhan) articulada por la República Popular de China desde 2005, como manual de cómo deben ser sus relaciones exteriores y qué papel ha de tener China en el concierto internacional. Esa doctrina articula conceptos confucianos, como la armonía, adaptados a la especificidad de las relaciones exteriores. Éstos se ligan a otros desarrollados por el gobierno chino, como el nuevo concepto de seguridad, donde se considera que la economía internacional debe ser la base de la seguridad global en un marco de beneficio mutuo y de prácticas entre iguales; o como el que define que las relaciones entre los Estados deben basarse en cinco principios básicos: respeto a la soberanía e integridad territorial, no agresión, no interferencia en los asuntos internos del otro, igualdad y beneficio mutuo, y coexistencia pacífica (Rocha Pino, 2006: 695 y 696; Guijin, 2004; Eisenman y Kurlantzick, 2006).

China busca con todo ello caracterizarse no sólo como potencia emergente sino como un gran poder pacífico, no amenazante y eminentemente colaborativo y responsable de su papel en el mundo.

Se trata de una perspectiva que significa una clara evolución en la trayectoria de más de 50 años de relaciones con los países africanos (Garza, 1975; Liu, 2008). Se ha pasado de una ligazón internacional basada en conceptos ideológicos en la época maoísta, seguida del mantenimiento de un bajo perfil en la relaciones exteriores en la época de Deng Xiaoping, a una terciada por la cuarta generación de líderes chinos basada en las relaciones comerciales y la explotación de recursos pautada por el pragmatismo y cooperación y beneficio entre iguales.

\section{Medio siglo de relaciones entre la República Popular China y el África subsahariana}

Tal como apunta Martins (2005), esta relación chino-africana tiene sus raíces en el momento fundacional de la República Popular China en 1949. La diplomacia china de esos años, incipiente, balbuceante y con una fuerte carga ideológica derivada de la dialéctica del marxismo, se basaba en la presunción del entendimiento entre los pueblos que habían estado o estaban oprimidos.

Enrui Yang (2005) plantea cuatro fases en ese marco de relaciones exteriores que la República Popular China ha mantenido en la esfera internacional y por ende con los países africanos. Éstas son: 
1. La inclinación única. Unión con los otros desfavorecidos (1949-1950).

2. Altruismo revolucionario y la diplomacia entre pueblos (1951-1956).

3. Antagonismo chino-soviético y la revolución mundial (1957-1972).

4. Uniéndose con el tercer mundo y con Estados Unidos (1972-1979).

Ciertamente, la evolución de las relaciones bilaterales entre China y los países africanos se fue dando con base en una serie de coordenadas eminentemente ideológicas, al menos hasta el inicio de relaciones bilaterales entre Estados Unidos y la República Popular China en 1971. Primero con las aproximaciones muy limitadas en el marco de las buenas relaciones chino-soviéticas. Más tarde, ya en la segunda fase, y con progresivo distanciamiento entre la República Popular China y la Unión Soviética, se establece esa diplomacia entre pueblos, resultado, sin duda, de los influjos de la conferencia de Bandung de 1955, donde se manifiestan las ideas anticolonialistas y antiimperialistas, pero sobre todo como una respuesta o solución a la nueva situación de China en el contexto internacional (Adie, 1964; Ansprenger, 1964).

La diplomacia china ve necesaria una confraternización entre los países que han surgido tras la caída de los imperios coloniales, en África y en Asia; de ahí su adscripción inicial al movimiento de los países no alineados. Todo ello tenía como finalidad el posicionamiento internacional frente al peso creciente de Estados Unidos en la zona y la transmisión del ideal maoísta y su aplicación a otros lugares del orbe. Esos postulados de Bandung y otros extraídos de la transmisión superficial de las bondades del comunismo a la china van a verse reflejados en las doctrinas políticas de líderes africanos como el congolés Patrice Lumumba o el ghanés Kwame Nkrumah, activos en esos años.

La tercera fase de la evolución diplomática china se da tras la ruptura con la Unión Soviética. En ésta, la URSs para el maoísmo ya no cumple el paradigma de baluarte ideológico y China pretende obtener esa llama, sumada a la consideración de que la URSS y Estados Unidos son los enemigos a eliminar. Esa llama se transmuta en ocho principios de ayuda internacional (Martins, 2005: 255) y que China va a tratar de aplicar, especialmente en África. Esos principios, respecto a la propia independencia, a las problemáticas internas, ayuda mutua, cooperación, entre otros, no serán óbice para que la China de Mao dé apoyo a los independentistas argelinos inmersos en su guerra de independencia, que reciben el apoyo soterrado militar chino; el apoyo explícito a Nasser durante la crisis del canal de Suez o la relación retroalimentada mutuamente entre el primer ministro de Ghana, Nkrumah, y Mao, que apro- 
vechando los flujos comerciales del cacao, sirvió para la construcción de ese país, antigua colonia inglesa del África Occidental.

Entre 1955 y 1977 China vendió 142 millones de dólares en armamento a África, a la par que las universidades chinas abrieron las puertas a más 15,000 estudiantes africanos.

La cuarta fase coincide con la real politik y el dominio hegemónico de Estados Unidos, que obliga a un acercamiento entre los dos países. Sin duda, las consecuencias del acercamiento con los estadounidenses permitieron una mayor aproximación china a los "otros pueblos". Una de ellas fue la obtención en 1971 de uno de los sitios permanentes del Consejo de Seguridad de la ONU por parte de China, en detrimento de Taiwán. Ésta contó con el voto favorable de 26 países africanos. Un hecho que permitirá unas relaciones entre África y China más explicitas, pero que obligaron a la ruptura de relaciones con Taiwán de no pocos países africanos. Se trata de una estrategia de Pekín por aislar internacionalmente a la "isla rebelde", que aún pervive. Actualmente sólo Malawi, Sao Tomé y Príncipe, Burkina Faso, Gambia y Swazilandia mantienen relaciones con Taiwán, y el goteo en cuanto a la ruptura de relaciones se ha dado desde esa fecha con un ligero retroceso, luego corregido en la década de los noventa.

Todo ello explica que entre 1970 y 1978 China concediese ayuda a países como Benín, Islas Mauricio, Madagascar, Nigeria, Ruanda, Togo, Nigeria, Alto Volta, Zaire, Túnez y Camerún (Ecowas-SWAC/OCDE, 2006: 2) y que ésta fuese una vez y media mayor que la otorgada entre 1950 y 1970 (Martins, 2005: 257). En esos años se va a dar un proyecto que supone el primer antecedente palpable y de calado, de lo que hoy en día es una realidad: la inversión china en África. Entre 1970 y 1975 se construyó el ferrocarril Tanzania-Zambia con un costo de 455 millones de dólares (Martins, 2005: 257).

Esa actividad, a caballo entre la inversión y la ayuda técnica, se ralentizó en la época de Deng Xiaoping. En esos años China estaba más preocupada por su reforma económica y con los cambios que se estaban dando en el mundo, especialmente tras la caída del Muro de Berlín, y requería unas relaciones exteriores plácidas y de bajo perfil. Sería, a partir de la segunda mitad de la década de los noventa del siglo $\mathrm{xx}$, cuando China retomaría desde una perspectiva económica globalizadora esa relación chino-africana, promoviendo a inicios del siglo XXI el FOcAC.

China cada vez más debe presentar su propuesta como potencia económica emergente, necesita dónde invertir, dónde colocar sus productos, pero 
también dónde adquirir materias primas y cubrir sus necesidades energéticas para continuar su avance económico. A su vez, como futura potencia mundial debe articular una presencia más integral en el contexto mundial, enmarcada en la doctrina del desarrollo pacífico. Para el caso africano la tendencia parece ser ésa, ya que China mantiene relaciones diplomáticas con 48 países africanos de un total de 53, y se ha involucrado en operaciones de paz de Naciones Unidas en Liberia o en la República del Congo.

En 2004, más de 1,500 soldados del Ejército Rojo mantenían su presencia como cascos azules en África y ha apoyado explícitamente a que los candidatos africanos: Sudáfrica, Egipto y especialmente Nigeria ocupen un asiento permanente en el Consejo de Seguridad de la ONU (Servant, 2005).

Queda claro, pues, que la diplomacia china en más de 50 años ha dado un cambio copernicano respecto a su relación con el continente negro. Se ha desprendido del pasado ideológico para acometer con una enorme practicidad y con un marcado sesgo económico su política exterior en el continente sobre principios como la confianza mutua, el beneficio recíproco, la igualdad de las partes, la no injerencia en asuntos internos y la coordinación.

\section{Bases de las actuales relaciones de la República Popular China con África}

El principal detonante de ese nuevo marco de relaciones entre China y África fue la gira del primer ministro chino Jiang Zemin por África en 1996, donde proclamó los principios que regirían las relaciones entre el continente y su país. Esos principios, centrados en el binomio beneficio mutuo y no injerencia en asuntos internos, fueron consolidados en el Forum on China-Africa Cooperation (FOCAC), creado en octubre de 2000 con la asistencia de 45 países africanos y 17 organismos regionales e internacionales en Pekín. El mismo foro se volvió a reunir en diciembre de 2003 en Addis Abeba, capital de Etiopía, país con importantes inversiones chinas en el sector de las obras públicas, en donde se firmaron acuerdos por 460 millones de dólares entre 17 empresas chinas y sus pares africanas (Letian, 2005; Blenford, 2007; Hurst, 2006; Shinn y Eisenman, 2005).

A lo largo de 2004 Hu Jintao realizó diversas visitas a países africanos, concretando acuerdos especialmente en torno a la extracción y suministro de petróleo con Gabón, Nigeria y Angola. El 12 de enero de 2006 el gobierno 
chino presentó un símil de libro blanco — su título en inglés: China’s African policy - que explicita las relaciones que regirán entre China y los países africanos, basadas en el beneficio mutuo, la cooperación igualitaria, la cooperación militar, etcétera (Wenping, 2007). Entre abril y junio de ese mismo año, $\mathrm{Hu}$ Jintao y el primer ministro Wen Jiabao visitaron 10 países africanos, y al siguiente (2007) el ministro de asuntos exteriores Li Zhaoxing visitaría siete más: Benín, Botswana, Guinea Bissau, Guinea Ecuatorial, Eritrea, Chad y República Centroafricana.

En noviembre de 2006, de nuevo en Pekín, 48 máximos mandatarios africanos se volvieron a reunir en la tercera ronda del FOCAC. En esa ocasión el gobierno chino aprovechó para el lanzamiento del plan New Partnership for Africa's Development (NEPAD), que busca activar la participación de empresas chinas en mercados estratégicos africanos. Ese plan había surgido al amparo de la firma de la declaración conjunta: New Asian-African Strategic Partnership en el marco del Asian-African Summit, organizado en Yakarta entre el 20 y el 24 de abril de 2005, con el fin de conmemorar el 50 aniversario de la conferencia de Bandung.

El NEPAD recogía las nuevas premisas de la sociedad entre chinos y africanos que, como nos indica Aicardi (2004), se iban a concentrar en países africanos de alto potencial, ya fuese por la disponibilidad de materias primas, ya fuese por ser mercados potenciales o por tener una influencia diplomática significativa en la región. Además, el plan chino preveía facilitar 3,000 millones de dólares en préstamos y 2,000 millones más en créditos preferentes para los próximos tres años, es decir hasta 2009; consolidar un fondo de desarrollo de 5,000 millones de dólares para promover y apoyar las inversiones de empresas chinas en el continente africano; anular 10,000 millones de deuda de los países más pobres; establecer de tres a cinco zonas de cooperación en África; formar a 15,000 profesionales africanos; enviar expertos en tecnología agrícola; implementar centros de tratamiento de la malaria y sida; acrecentar la cooperación antiterrorista judicial, y aumentar el flujo exportador (Manji y Marks, 2007: 22; Wenping, 2007).

Ese despliegue diplomático perseguía fortalecer el posicionamiento como socio estratégico de China en la región, no sólo ante las potencias occidentales sino también otras economías emergentes como India, que han incrementado sustancialmente sus inversiones en la zona. 


\section{Algunos datos económicos de la relación China y el África subsahariana}

El resultado del crecimiento de la relación de China con los diversos países del África subsahariana se muestra fehacientemente en las cifras económicas. Como se puede observar en el cuadro 1, la inversión china en África pasó de los 85 millones de dólares en el año 2000 a 1,210 millones de dólares en 2004 (UNCTAD/FDI/TNC, 2006). Los flujos inversores evidencian esa evolución diplomática a la que arriba aludíamos y el progresivo interés de China por la región, provocado por las expectativas que genera en cuanto mercado de colocación de productos chinos y también como territorio de dónde extraer recursos de interés para el gigante asiático.

No se debe olvidar, sin embargo, la presencia inversora de otras economías emergentes asiáticas, por ejemplo la India o Malasia, con flujos mayores en cantidad y en el tiempo, o la amenaza de otros competidores como Corea del Sur o Singapur. Pudiera parecer que en cuanto a la inversión, la República Popular China busca un mayor posicionamiento como socio prioritario o estratégico no sólo frente a las potencias occidentales sino a otros competidores asiáticos.

En cuanto a las exportaciones chinas a la África subsahariana, para el año 2005 fueron por valor de 9,590 millones de dólares, frente a unas importaciones valoradas en 10,950 millones, según datos del Ministerio de Comercio chino. Ese mismo organismo estima que se debe elevar el volumen comercial bilateral a 100,000 millones de dólares para 2010 (Xinhuanet, 2006). Éste en 2005 era de 55,500 millones de dólares, cinco veces y media superior al de 2001 y 18 veces superior al de 1995 (Iranzo y Herrero, 2007: 15). En 2007 el mismo alcanzaba cifras en torno a los 73,000 millones de dólares, un crecimiento que hacía que en 2004 la República Popular China se convirtiese en el tercer socio comercial de África, por detrás de Estados Unidos y Francia.

Con todo y eso se trata aún de una relación que puede crecer, ya que es más cualitativa que cuantitativa y muy dispar entre las partes; por ejemplo, el comercio exterior desde el África subsahariana representa sólo entre 2.5 y $3.0 \%$ del comercio exterior de China, y en el año 2005 las inversiones de ésta en África sólo representaban 10\% del total de las que la República Popular realiza en el concierto internacional (Iranzo y Herrero, 2007: 16; Ecowas/ SWAC/OCDE, 2006: 4). Asimismo, en 2005 las inversiones chinas representa- 


\section{Cuadro 1}

Flujos de inversión y stocks acumulados de la República Popular China en África (En millones de dólares)

\begin{tabular}{crc}
\hline Año & Flujos de inversión & Stock de inversiones \\
\hline 1990 & & 49.2 \\
1991 & 1.5 & \\
1992 & 7.7 & \\
1993 & 14.5 & \\
1994 & 28 & \\
1995 & 17.7 & \\
1996 & - & \\
1997 & - & \\
1998 & - & \\
1999 & 42.3 & \\
2000 & 85 & \\
2001 & 24.5 & \\
2002 & 30.1 & \\
2003 & 60.8 & \\
2004 & 1,210 & \\
2005 & 1,610 & \\
\hline
\end{tabular}

Suma de inversiones.

Fuente: UNCTAD/FDI/TNC (http://www.unctad.org/fdistatitics).

ban sólo 3.27\% del total de inversión extranjera directa en África, cuantificada en 36,000 millones de dólares (UNCTAD, 2007).

Los países africanos —aquí debemos incluir los del arco mediterráneo y Sudáfrica- mantienen un régimen igualitario de exportaciones e importaciones, aunque se puede vislumbrar un incremento del valor de lo que China extrae del continente respecto a lo que los africanos compran a China. Según un estudio de Ecowas (2006: 5), las importaciones de los países subsaharianos desde China eran de 4,205 millones de dólares, y las exportaciones chinas al África subsahariana eran de 4,916 millones, considerando el promedio entre 1993 a 2004.

Según datos de la United Nations Conference on Trade and Development (UNCTAD), para 2005 el África subsahariana básicamente importaba de China bienes de consumo, $16 \%$ en textiles, $14 \%$ en zapatos y ropa, $8 \%$ en vehículos y $8 \%$ en equipos de telecomunicaciones, entre otros. 
En cuanto a las exportaciones subsaharianas hacia la República Popular China, éstas básicamente son recursos mineros, destacando sobremanera el petróleo, que suponía $71 \%$ de las mismas en 2006. Los principales países exportadores son Sudán, Angola y Nigeria. Los otros rubros con cifras significativas por lo que se refiere a las exportaciones son: el hierro, 13\% del total; las maderas preciosas, $2 \%$; las piedras preciosas, $3 \%$, y una cierta especialización en algodón, $4.2 \%$ en 2006, concentrada en países como Mali, Chad, Benín y Burkina Faso. En un análisis más pormenorizado se pueden detectar productos concretos, como el cobalto, que sin destacar porcentualmente en el monto total de las exportaciones, permiten a China mantener el monopolio de algunos subproductos elaborados con éste, como es el polvo de cobalto, clave para la preparación de metales sintetizados duros y para imanes.

En el cuadro 2 se ilustra esa predilección por los recursos mineros de las inversiones de empresas chinas en África. Una propensión que, por un lado, busca nutrir al mercado industrial del gigante asiático altamente demandante de esos recursos y, por otro, atiende propuestas de inversión de no exentar de oportunidad y control en el largo plazo. Aquí la estrategia china es clara: invertir en maquinaria y recursos económicos con el fin de garantizar la extracción rápida de esos recursos y contratar mano de obra local, supervisada por trabajadores chinos emigrados, aprovechando los escasos marcos legales de protección laboral que se dan en los países del África subsahariana.

\section{El papel del petróleo en las relaciones entre China y el África subsahariana}

En primer lugar, conviene decir que el papel de China en el África subsahariana respecto al petróleo es un claro ejemplo de su posicionamiento en relación con la geoestrategia global por el petróleo (Cole; 2003; Hurst, 2006). China ve en algunos países del África subsahariana, a proveedores petrolíferos de primer orden, y más si consideramos que en 2006 71\% de las exportaciones africanas hacia China eran de crudo. Los países productores africanos con estrechas relaciones con el gobierno chino vienen a cubrir parte de las necesidades de abastecimiento del gigante asiático. Cabe recordar que es el segundo consumidor mundial —6.59 millones bdp (2005) —- que debe importar más de $50 \%$ de ese consumo. Además se estiman unas necesidades de importación de crudo de 10.9 millones bdp para el año 2025 (Hurst, 2006: 3). Igualmente conviene mencionar que entre 1998 y 2003, 60\% de las remesas de petróleo 


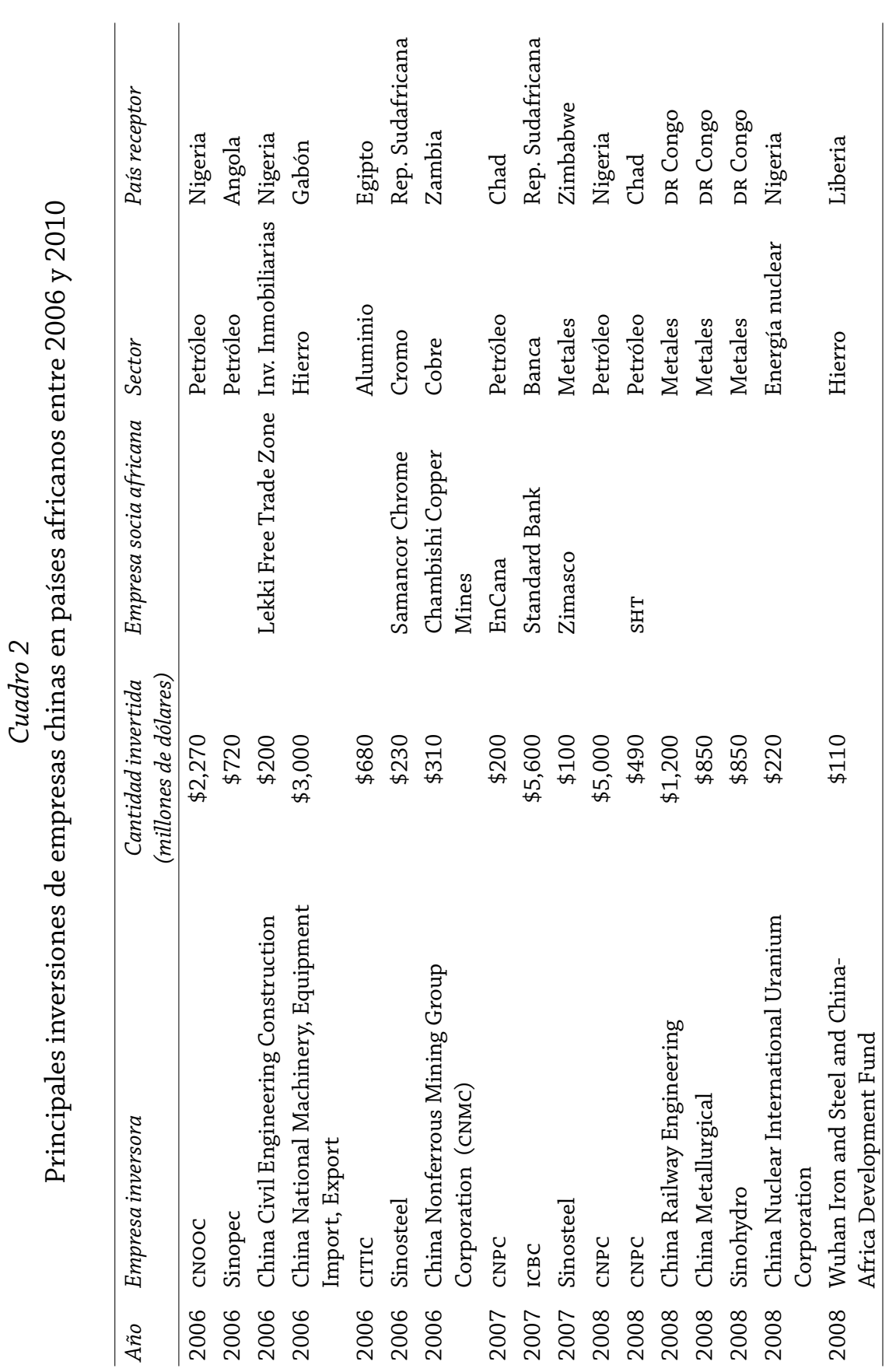




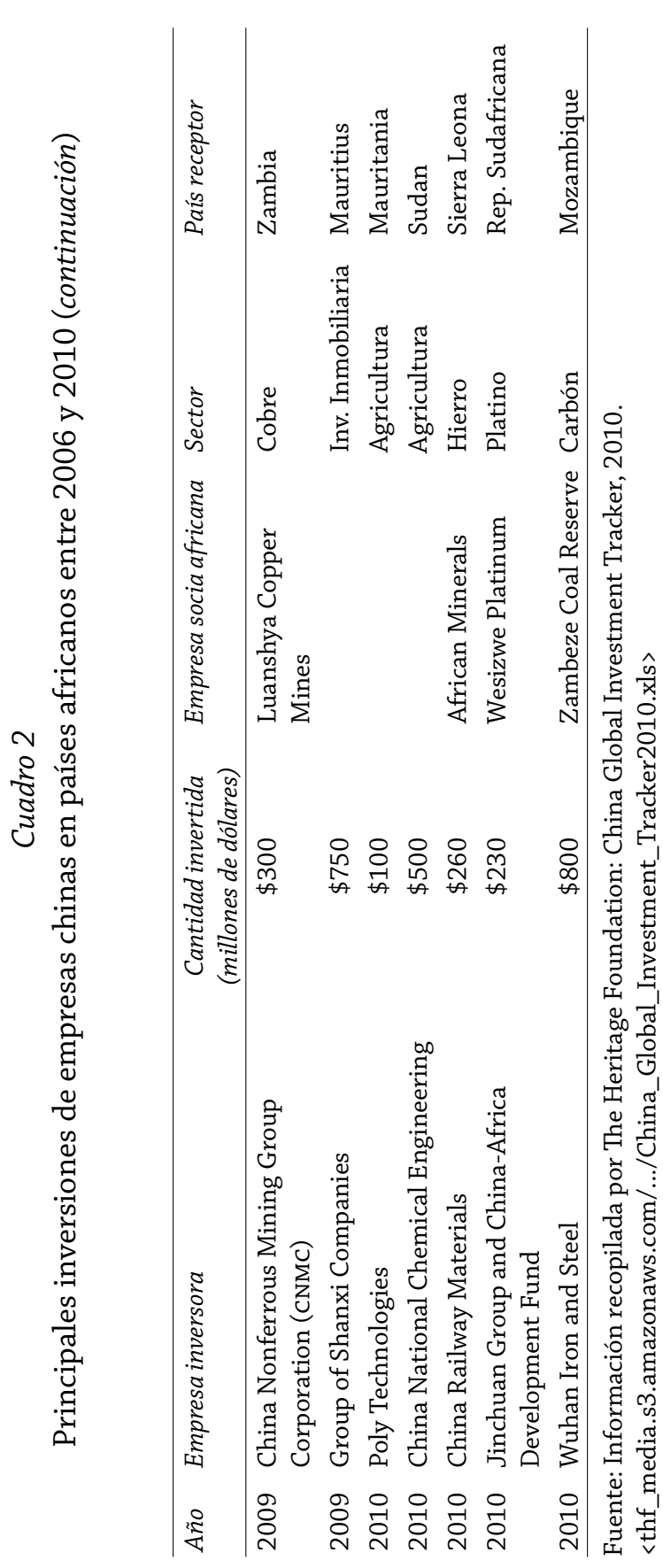

60 México y la Cuenca del Pacífico. Año 14, núm. 40 / enero - abril de 2011 
a China provenían de Oriente medio. La conflictividad en esa zona ha sido un factor determinante para que el gigante asiático busque otras fuentes de exportación; para ello el Âfrica subsahariana era un campo relativamente nuevo y poco explorado. La expansión y la progresión están siendo muy rápidas, puesto que en 2005 ya suponía 30\% de las importaciones totales de crudo de China. Con todo, algunos analistas señalan que la participación china en el mercado del petróleo africano se debe relativizar, puesto que aún es baja en comparación con las operaciones que realizan otros países. Además, si bien las importaciones de petróleo han crecido en nueve veces entre 1998 y 2005, éstas se concentran en unos pocos estados en donde China no ha encontrado la competencia de otros países, porque en la mayoría de los casos se trataba de explotaciones rechazadas por consideraciones técnicas, políticas y económicas (Downs, 2007: 44).

Esas exportaciones de petróleo africano van asociadas a las inversiones en la extracción, distribución y refinado, dadas las escasas capacidades en esas áreas de los países productores. Para ello China ocupa a sus tres principales empresas del sector: China Petrochemical Corporation (Sinopec), China National Petroleum Corporation (CNPC) y China Offshore Oil Corporation (CNOOC).

Aunque la relación petróleo-África-China abarca a diversos países del continente negro, especialmente en terrenos de prospección donde hay acuerdos firmados con Argelia, Angola, Congo, Gabón, Mali y Sudán, y en materia de compra de producción como en Nigeria, sólo cuatro se pueden considerar como principales proveedores de China: Angola, que representa 45\% de las exportaciones de crudo; Sudán, 18\%, República del Congo, 14\%, y Guinea Ecuatorial, 9\% (Ecowas, 2006: 10). Todos ellos son ejemplo de una ambivalente actuación china en el África subsahariana, regida por el pragmatismo, la inversión como sustituto de la ayuda y la negociación con las élites gobernantes sin intromisión en cuestiones de gobernabilidad interna.

En este sentido es paradigmática la actuación de China en Sudán respecto al petróleo (Sichor, 2005: 9-11). En 1999 las importaciones chinas de petróleo desde Sudán eran de sólo 266,126 toneladas, un poco menos de 1\% del total de sus importaciones petrolíferas. Año con año, las mismas se han ido incrementando hasta llegar en 2001 a 3'312,591 toneladas, que representaban $4.72 \%$ del total de las importaciones chinas de crudo. Un año más tarde ascendieron a 6'425,447 toneladas, 9.26\% del total, convirtiendo a Sudán en el cuarto proveedor de crudo para China, detrás de Arabia Saudita, Irán y Omán. Sin embargo, con todo y que la explotación china de petróleo en el 
país se incrementó en 2004 y 2005, declinó el porcentaje en el volumen de las importaciones totales chinas de petróleo. En esos años el gigante asiático derivaba hacia una creciente diversificación de fuentes, tanto en la región subsahariana como en el Asia central. Era también una deriva a causa del conflicto de Darfur que afectaba a la zona.

Paralelo a ese flujo petrolero, se registró un importante volumen de inversiones chinas en el país. La United Nations Conference on Trade and Development (UNCTAD) señala que en 2005 Sudán recibió 351.5 millones de dólares en inversiones chinas. Éstas se destinaron a la construcción de refinerías, proyectos de industrias textiles y pesqueras, presas, construcción de infraestructura como puentes y carreteras, casi todas vinculadas con la movilidad y disponibilidad del oro negro de este país africano. Éste se localiza en el sudeste del país, alejado del único puerto capaz de extraerlo, Port Sudan, en el Mar Rojo (Askouri, 2007: 101-103).

A cambio de explotar ese petróleo, China ha ignorado los llamados de la comunidad internacional en contra del régimen de Omar Hassan al Bachir, ahora acusado del genocidio de Darfur por el Tribunal Penal Internacional; ha bloqueado las posibles sanciones contra un régimen que se enriquece con las inversiones chinas, mientras ignoraba los derechos humanos de sus empobrecidos ciudadanos (HRW, 2003: 456-468). Así, por ejemplo, la República Popular China donó 400,000 dólares a la Unión Africana para la crisis de Darfur a cambio de evitar sanciones a Sudán en el Consejo de Seguridad de las Naciones Unidas. Como contraparte, el régimen sudanés protege las inversiones chinas, desplazando y asesinando poblaciones "molestas" próximas a los proyectos chinos (Askouri, 2007: 104-107). Conviene decir que los campos petrolíferos chinos en algunos casos se encuentran en áreas afectadas por incursiones de guerrillas opositoras al régimen de Jartum.

El principio que sustenta esa actuación china es el de la no injerencia en los asuntos internos de los estados. Sin embargo, esas posiciones están cambiando debido a las presiones internacionales para el cumplimento de los acuerdos sobre Darfur de Naciones Unidas, donde la diplomacia china ha aproximado a las partes (Gill, Hiang y Morrison, 2007: 15; Wenping, 2007: 35; Guijin, 2008) y por la perentoria necesidad china de no emborronar su imagen internacional durante los años previos a la celebración de los Juegos Olímpicos en China, más cuando organizaciones no gubernamentales occidentales señalaban al régimen de Pekín como uno de los máximos valedores del régimen genocida sudanés. Aunque esos hechos son irrefutables, conviene 
añadir que las operaciones petrolíferas chinas en Sudán se realizan a través de Greater Nile Petroleum Operating Company (GNOC), un consorcio donde China National Petroleum Corporation (CNPC) es el principal accionista, junto con la empresa malaya Petronas, la sudanesa Sudapet y la ONGC Videsh de la India (Hurst, 2006: 7).

Por otro lado, también hay que señalar que la perversa dinámica de exterminio indiscriminado de los opositores rebeldes al régimen sudanés desarrollada desde la década de los ochenta, también ha afectado a otras operadoras petroleras, como las canadienses Arakis Energy Corp. y Talisman Energy Inc., la sueca Lundin Oil Company o la estadounidense Chevron, siendo en todos los casos un ejemplo de la falta de escrúpulos de muchas multinacionales petroleras o de una condición asumible para poder operar en ese país (HRW, 2003).

Otro ejemplo de la ambivalencia china respecto al petróleo subsahariano, lo encontramos en Angola, el principal exportador africano de petróleo hacia China, donde la necesidad de crear infraestructura extractiva para el petróleo descubierto en el país provocó que el gobierno chino se aplicase en ayudar a la antigua colonia portuguesa devastada tras años de guerra civil. La ayuda en forma de créditos con garantía de las extracciones petroleras, inversiones y asistencia al desarrollo, valorada entre 8,000 y 12,000 millones de dólares, se destinaba en principio a la reconstrucción de país y también a dotar de infraestructura e inmuebles que generan réditos políticos a las élites del país. La contrapartida ha sido el desplazamiento de soldados angoleños a la zona de Cabinda, donde se concentra 60\% del petróleo del país. La actividad de estos militares ha sido denunciada por Human Rights Watch, por el nivel de detenciones y torturas a las que se somete a la población civil en aras de una protección del recurso petrolero preciado por los chinos (Chan-Fishel: 2007: 145 y 146).

La relación china con el petróleo africano va más allá, puesto que las necesidades de movilidad y producción de este recurso requieren de diversas infraestructuras. Ésas son objeto de inversión china y de colaboración con otros países africanos. Hay algunos ejemplos de esto: la extracción y refinado de gas en Argelia, desarrollada bajo el paraguas de la cooperación técnica científica y la sinergia económica, eficazmente promovida por Hu Jintao a partir de 2004 (Porcu, 2006); el anuncio de la construcción de la primera refinería de petróleo en N’Djamena, capital de Chad (BBC Chinese, 2007) y las prospecciones off shore en la República del Congo por Sinopec (Iranzo 
y Herrero, 2007); las operaciones de prospección en la región de Gambella, en Etiopía, bajo la sospecha de violaciones de los derechos humanos (Hurst, 2006: 8), y la donación de ayuda china tras el tsunami de 2004 a Somalia, a cuenta de prospecciones en el territorio, donde hay presencia de uranio y petróleo (Blendford, 2007).

Finalmente, queda aún en el aire el papel que el petróleo africano ha de desempeñar respecto a la generación de empresas extractivas y complementarias autóctonas que permitan la inserción real de las economías africanas en el contexto global (Boardman, 2007: 34). Igualmente, la situación analizada respecto al petróleo y China, alumbra los fantasmas de la dutch disease, dada la dependencia de la extracción energética por parte de potencias extranjeras.

\section{Las materias primas subsaharianas, el otro interés chino}

No se debe ignorar que existen otras materias primas susceptibles del interés chino en el África subsahariana, dados los altos niveles de consumo que tiene el gigante asiático. De nuevo, la ambivalencia planea en la relación Chinamaterias primas. Por un lado, lleva asociada la voracidad explotadora, junto con la generación de numerosos problemas medioambientales, así como un bajo nivel de respeto de los derechos laborales. Los casos empiezan a poblar la geografía del África subsahariana; entre éstos conviene destacar el caso de la mina de hierro de Belinga, en Gabón. Se trata de una de las últimas grandes explotaciones de hierro del planeta, ahora bajo la concesión de Sino Steel Co. y China National Machinery and Equipment Import and Export Corporation (CEMEC).

Esta última firma se comprometió al desarrollo de un ferrocarril que permitiese la extracción del mineral; a cambio, opera con total impunidad respecto al medio ambiente (Legault, 2008) la explotación de la mina de cobre BGRIMM Zambia, propiedad en un 60\% de China Non Ferrous Metal Industries. Allí se documenta una escasa seguridad laboral y pronunciamientos antichinos por parte de los candidatos de la oposición que mediatizaron, por presiones diplomáticas, las elecciones en ese país centroafricano (Chan-Fishel: 2007: 147 y 148).

Casos similares se pueden presentar en la República Democrática del Congo, donde empresa chinas como Colec, Feza Mining o Nanjing Hanrui Cobalt Co Ltd se están haciendo con la propiedad de minas. En este caso, el interés chino no es sólo una necesidad de producto sino la voluntad de mantener el 
monopolio internacional de la venta de polvo de cobalto, usado por numerosas multinacionales del sector de la electrónica de consumo (Chan-Fishel: 2007: 148). Como también lo es por controlar recursos de utilidad en el futuro más o menos cercano, como el uranio en los yacimientos saharianos localizados en Nigeria (Michel y Beuret, 2009: 105 y ss.).

También en Gabón, la masiva explotación de maderas por parte de concesionarias chinas pone en entredicho este recurso y esquilma los bosques de este país del Golfo de Guinea. La causa no es sólo la voracidad sobre el producto, sino también las restricciones en China para la extracción de maderas locales. La madera, además, se convierte en un recurso susceptible de ser extraído de forma ilegal, lo que sucede en países como Camerún, Guinea Ecuatorial, Liberia o Mozambique, donde se encuentran empresas chinas que de forma encubierta operan y extraen ingentes cantidades de madera difícil de reponer, consolidando algo que ya empieza a ser conocido como el take away chino (Lemos y Ribeiro, 2007: 87-90).

\section{A manera de conclusión}

Como decíamos más arriba en relación con la geoeconomía: las acciones económicas devienen esenciales, pues llegan a modificar el espacio. Ésta es una construcción socioeconómica fruto de las interrelaciones de esas acciones. Esas interrelaciones espacializadas unas veces son de cooperación y otras conflictivas. Así sucede en el caso de la relación de la República Popular China con los países africanos. La ambivalencia de las relaciones establecidas, ora de cooperación, devengadora de asistencia y de ayuda externa, ora de generación de beneficios tras intervenir en procesos de inversión, son la estructura que se teje gracias a esas relaciones.

Sobre la misma, se posicionan elementos de negatividad, veraces y preocupantes, donde la presencia china se ve como la de una potencia colonizadora, extraordinariamente depredadora, interesada en la extracción de todo tipo de recursos y renuente a considerar los derechos laborales de los trabajadores africanos que intervienen en sus operaciones, y nada interesada en atender los derechos humanos, que son socavados de forma directa e indirecta por la agresividad de su intervención. Aspectos éstos que, por otra parte, son una carencia endémica e inherente del continente africano y por tanto una realidad difícil de atribuir sólo a la presencia china. 
Sobre esa malla, también se posicionan aspectos positivos. Por un lado, hay que señalar que el crecimiento comercial chino-africano que se ha venido dando en los últimos años, significa una oportunidad para los países africanos participantes, ya no sólo por la exportación de determinados productos léase recursos minerales y energéticos-, sino como importador de bienes de consumo producidos en China. Esto permite la activación de un mercado aún pequeño y débil: el propio mercado regional africano y, por ende, no pocas economías nacionales (Bordman, 2007). Una activación que ha significado una verdadera inundación de productos chinos en los países africanos, que encuentra entre los comerciantes locales sus principales introductores, como se documenta claramente en Senegal (Michel y Beuret, 2009: 125-129).

Los datos y los ejemplos nos hablan de una sinergia entre dos mercados derivados de una economía en auge y de unas economías en construcción; ésa es la tesis que parece apuntar Boardman (2007). No se debe obviar el papel de China tras su acceso a la Organización Mundial del Comercio (OMC) como activador de esa dinámica económica. Los efectos de ello ya se dejan sentir, por ejemplo en la reducción de las barreras de entrada que todavía existen de diversos productos, más de 190 en África para su libre acceso al mercado chino y otros tantos del lado chino para África, para ver que la emergencia de esta relación aún debe dar más frutos.

Igualmente, todo ello tiene una faceta notoriamente propositiva: la ayuda técnica asociada a las inversiones. Éstas han permitido la generación de programas, proyectos, la construcción de infraestructuras, a la par que ofertas laborales diferentes e incluso inéditas para no pocas regiones donde la inversión china se deja sentir. Éste es el caso, por ejemplo, de las acciones emprendidas en Etiopía. Allí podemos constatar una joint venture entre la etíope Tacase Hydropower Station y la China Hydropower Joint Group que desarrolla un importante proyecto de gestión de agua en ese país y que a la vez lleva asociado la construcción de una carretera por parte de la China Road and Bridge Corporation ( $\mathrm{CRBC}$ ). Ambos proyectos son generadores de mano de obra en cantidades significativas y permiten la dotación de infraestructuras donde eran muy escasas (Blenford, 2007).

Aún con esa situación al parecer halagüeña para ambos lados, no se debe obviar que China usa guante de seda en unas relaciones diplomáticas más o menos consensuadas, más o menos teñidas de buena voluntad en cuanto a la procuración de desarrollo para el África subsahariana, para enmascarar una voracidad en materias primas y necesidad de colocación de productos que 
China desarrolla para prolongar su crecimiento económico y determinar su posicionamiento en el mundo. Esto, visto desde la geoeconomía, no deja lugar a dudas en cuanto a que la República Popular China ha tomado a África como un espacio donde experimentar con hechos un discurso ideológico en relación con la diplomacia que desea desarrollar en los años venideros. Éste, basado en estrategias con apariencia de ganadoras para ambas partes, eminentemente práctico y equilibrado entre la ayuda, la cooperación y la inversión, parece esconder una inagotable necesidad de todo tipo de recursos naturales, ya no sólo para mantener su crecimiento económico sino para posicionarse de forma contundente en un contexto internacional marcado por la competencia entre naciones por obtener los recursos que permitan sostener su crecimiento y su estabilidad actual. Hecho éste que de algún modo está planteando una nueva correlación en las relaciones internacionales contemporáneas y acentuará las estrategias de los diferentes países en los años venideros. mig

\section{Referencias bibliográficas}

Adie, W. A. C., Chinese Policy toward Africa, The Scandinavian Institute of African Studies, Upsala y Estocolmo, 1964, pp. 43-63.

Alves, A. C., "Emerging postcolonial solidarities: China's new economic diplomacy towards subsaharian Africa", 16th Biennial Conference of the Asian Studies Association of Australia, Wollongong, 26 al 29 de junio de 2006.

Aning, K., y D. Lecoutre, “China's ventures in Africa”, African Security Review, vol. 17, núm. 1, Institute for Security Studies, Tshwane (Pretoria), República Sudafricana, 2006.

Ansprenger, Franz, Communism in Tropical Africa, The Scandinavian Institute of African Studies, Upsala, 1964, pp. 75-100.

Askouri, A., "Pueblos desplazados, comunidades destruidas... Algunas inversiones de China en Sudán”, en F. Manji, y S. Marks (eds.), China en África. ¿Ayuda o arrasa? Perspectivas africanas sobre la irrupción del gigante asiático y sus consecuencias, Oozebap, Nairobi, 2007.

Ávila Álvarez, A., y M. A. Díaz Mier, "La geoeconomía: Instrumento de análisis de las relaciones económicas internacionales”, VI Reunión de Economía Mundial. Reunión de Economía Mundial, núm. 6, Servicio de Publicaciones de la Universidad de Extremadura, Badajoz, España, 2004.

BBC Chinese, "China National Petroleum Corporation to build Chad's first oil refinery", BBC Chinese News, 26 de octubre de 2007. < http://www. 
chinamemo.org/chinascope/briefing/geo-strategic-development/2757> Consultado el 12 de noviembre de 2007.

Blenford, A., "China in Africa: Developing ties. Friend or foe?", BBC News, 26 de noviembre de 2007. < http://news.bbc.co.uk/2/hi/africa/7086777. stm> Consultado el 12 de noviembre de 2007.

Boardman, H., Africa's silk road. China and India's New Economic frontier, The International Bank for Reconstruction and Development/The World Bank, Washington, 2007.

Braud, P. A., La Chine en Afrique: anatomie d'une nouvelle stratégie chinoise, Institute for Security Studies, Tshwane (Pretoria), República Sudafricana, octubre 2005. 〈http://www.iss-eu.org/new/analysis/analy124.pdf>

Brautigam, D., The dragon's gift. The real story of China in Africa, Oxford University Press, Londres, 2009.

Burke, C., "Lazos económicos emergentes entre China y África. África, la nueva frontera china", Boletin GovernÁsia, núm. 6, Casa Asia, Barcelona, 2008. < http://www.casaasia.es/governasia/boletin/>

CCA's, China and Africa Understanding the Growing Trade and Investment Relationship, The Corporate Council of Africa, Washington, abril, 2006.

CCHS, "China's development assistance to Africa", The China Monitor, núm. 28, Stellenbosch University-Centre for Chinese Studies, South Africa, abril 2008.Chan-Fishel, M., "Impacto ecológico ¿Más de lo mismo?”, en F. Manji, y S. Marks (eds.), China en África. ¿Ayuda o arrasa? Perspectivas a fricanas sobre la irrupción del gigante asiático y sus consecuencias, Oozebap, Nairobi, 2007.

Cole, B., "Oil for the Lamps of China-Beijing's 21st-Century Search for Energy", McNair Paper, núm. 67, National Defense University-Institute for National Strategic Studies, Washington, 2003.

Cooper Ramo, J., The "Beijing Consensus", The Foreign Policy Center, Londres, mayo, 2004.

Davies, P., China and the end of poverty in Africa-towards mutual benefit?, The Swedish Development Aid Organization Diakonia, European Network on Debt and Development (Eurodad), Sundbyberg, Suecia, 2007.

DFID, Achieving the Millennium Development Goals in Africa: Working with China, Department for International Development, Londres, abril, 2008. < http://www.dfid.gov.uk/>

Dollar, D., "Lessons from China for Africa", Policy Research Working Paper, núm. 4531, The World Bank, East Asia and Pacific Region, China/Mongolia Department, Washington, febrero, 2008. 
Downs, E., "The fact and fiction of sino-african energy relations", China Security, vol. 3, núm. 3, World Security Institute, Washington, verano, 2007, pp. 42-68.

Economic Commission for Africa (ECA), Africa and the Monterrey Consensus: Tracking Performance and Progress, ONU-Economic Commission for Africa, Nueva York, 2008.

Ecowas-SWAC/OCDE, "Africa in China. Economy Series", The Atlas on Regional Integration, diciembre, 2006. <www.atlas-westafrica.org>

Edinger, H., H. Herman, y J. Jansson, New impulses from the south: China's engagement of Africa, University of Stellenbosch-Centre for Chinese Studies, South Africa, mayo, 2008.

Eisenman, J., y J. Kurlantzick, “China's Africa Strategy”, Current History, mayo, 2006, pp. 219-224.

Enrui Yang, E., "Mao Zedong y Deng Xiaoping: Medio siglo de diplomacia china”, en X. Ríos (ed.), Política exterior de China. La diplomacia de una potencia emergente, Editorial Bellaterra, Barcelona, 2005, pp. 19-43.

García Encina, C., "La política africana de Pekín: ¿Oportunidad o amenaza?", África Subsahariana, ARI, núm. 27, Real Instituto Elcano, Madrid, marzo, 2006.

Garza Elizondo, H., China y el tercer mundo. Teoría y práctica de la política exterior de Pekín, 1956-1966, El Colegio de México, México, 1975.

Gill, B., H. Huang, y J. S. Morrrison, “Assessing China's Growing”, China Security, vol. 3, núm. 3, 2007, pp. 3-21.

Gill, B., y J. Reilly, "The Tenuous Hold of China Inc. in Africa”, The Washington Quarterly, vol. 3, núm. 30, The Center for Strategic and International Studies/The Massachusetts Institute of Technology, Cambridge, Massachusetts, 2007, pp. 37-52.

Goldstein, A., N. Pinaud, H. Reisen, y X. Chen, The rise of China and India: What's in it for Africa?, Centro de Desarrollo de la OCDE, París, 2006.

González, A., "La inserción de China en África: El juego de las grandes potencias y sus posibles efectos colaterales", Observatorio de Política China, Casa Asia e Igadi, Barcelona, 15 de abril de 2006. <http://www.igadi.org/ index.html>

Guerrero, D. G., y F. Manji (eds.), China's New Role in Africa and the South: A Search for a New Perspective, Fahamu and Focus on the Global South, Nairobi, Oxford y Bangkok, 2008. 
Guijin, L., China-Africa Relations: Equality, Cooperation and Mutual Development, Seminar on Sino-African Relations, Institute for Security Studies, Tshwane (Pretoria), República Sudafricana, noviembre, 2004.

- - Darfur and Sino-African Relations, Chatham House Paper, Londres, febrero, 2008.

Guo, S., China's peaceful rise in the $21^{\text {st }}$ century, Ashgate Publishing Ltd, Nueva York, s/f.

Hanson, S., China, Africa and Oil, Council on Foreign Relations, Washington, 6 de junio de 2008. < http://www.cfr.org/publication/9557\#3>

Holslag, J., "Friendly Giant? China’s Evolving Africa Policy", Asia Paper, vol. 2, núm.5, 24 de agosto de 2007.

Human Rights Watch (HRW), Sudan, Oil, and Human Rights, Human Rights Watch, Londres y Nueva York, 2003.

Hurst, C., China's Oil Rush in Africa, The Institute for the Analysis of Global Security, Washington, julio, 2006.

Iranzo, S., e I. Herrero, "La estrategia económica de China en África", Boletín Económico del ICE, núm. 2909, Instituto de Comercio Exterior, Madrid, 16-30 de abril de 2007, pp. 16-34.

Kaplinisky, R., D. Mccormick, y M. Morris, The impact of China on Sub Saharan Africa, Institute of Development Studies (IDS)-Asian Drivers Programme, Brighton, Reino Unido, 2006.

Keenan, Patrick J., "Curse or cure? China's investments in Africa and their effect on human rights”, 27 Berkeley J. Int'l Law, núm. 84, 2009.

Kurlantzick, J., Beijing's Safari: China's Move into Africa and Its Implications for Aid, Development, and Governance, China Program, Carnegie Endowment for International Peace, Washington, noviembre 2006.

Legault, G., “Africa's newest friends”, China Rights Forum, núm. 1, 2008.

Lemos, A., y D. Ribeiro, “ ¿Al fin somos los dueños o simplemente asistimos a un cambio de propietarios? Una opinión desde Mozambique”, en F. Manji, y S. Marks (eds.), China en África. ¿Ayuda o arrasa? Perspectivas africanas sobre la irrupción del gigante asiático y sus consecuencias, Oozebap, Nairobi, 2007.

Letian Pan, "China to promote cooperation with Ethiopia", Xinhua, 28 de noviembre de 2005. http://www.gov.cn/misc/2005-11/28/content_111610. htm > Consultado el 12 de noviembre de 2007. 
Liu, H., "La diplomacia cultural de China hacia los países africanos en el nuevo siglo. África, la nueva frontera china”, Boletin GovernÁsia, núm. 6, Casa Asia, Barcelona, 2008. <http://www.casaasia.es/governasia/boletin/>

Lorot, P. (dir.), Introduction á la Geoeconomie, Edit. Économique, París, 2000. Luttwak, E., "From Geopolitics to Geo-economics. Logics of Conflict, Grammar of Commerce", The National Interest, núm. 20, 1990, pp. 17-23.

- - The Endangered American Dream, Simon and Schuster, Nueva York, 1993. Lyman, P., China's rising role in Africa, presentation to the Us-China Commission, Washington, julio 21, 2005.

Manji, F., y S. Marks (eds.) China en África. ¿Ayuda o arrasa? Perspectivas africanas sobre la irrupción del gigante asiático y sus consecuencias, Oozebap, Nairobi, 2007.

Marks, S., "China in Africa, ¿ The new imperialism?”, Pambazuka News, núm. 244, Nairobi, 2 de marzo de 2006. www.pambazuka.org/en/category/ features/32432

Martins, D. A. E., "China en el liderazgo de los países subdesarrollados", en X. Ríos (ed.), Política exterior de China. La diplomacia de una potencia emergente, Editorial Bellaterra, Barcelona, 2005.

Melber, H. (comp.), “Trade, Development, Cooperation. What Future for Africa?”, Current African Issues, núm. 29, The Nordic Africa Institute, Upsala, 2005.

-— (ed.), "China in Africa”, Current African Issues, núm. 33, The Nordic Africa Institute, Upsala, 2007.

Méndez, R., y F. Molinero, "La herencia de la colonización y la crisis estructural de África subsahariana”, Espacios y sociedades. Introducción a la geografía regional del mundo, Ariel, Madrid, 2002, pp. 571-629.

Michel, S., y M. Beuret, China en África. Pekín a la conquista del continente americano, Alianza Editorial, Madrid, 2009.

Mills, G., "De la desesperación al renacer de la esperanza. El ciclo contemporáneo del desarrollo africano", África, Vanguardia Dossier, Barcelona, enero-marzo de 2008, pp. 14-22.

Mkandawire, T. Y., y C. C. Soludo, Our continent, our future. African Perspectives on Structural Adjustment, IDRC/Codesria/Africa World Press, Ottawa, Canadá, 1999. <http://www.idrc.ca/openebooks/855-4/>

Moumouni, G., "Domestic transformations and change in Sino-African Relations”, Working Paper, núm. 21, Center on China's Transnational Relations, The Hong Kong University of Science and Technology, Hong Kong, 2006. 
Niquet, V., "China's African strategy", La revue des revues, France Diplomatie, Janvier, 2007. <www.diplomatie.gouv.fr/fr/IMG/pdf/0805-Niquet-ANG. pdf>

Porcu, S., "Argelia: la sinergia económica con Pekín y la preocupación de Washington y París", Equilibri. Simply a new perspective on global affairs, 16 de noviembre de 2006. <http://www.equilibri.net/articulo/5345/Argelia la_sinergia_econmica_con_Pekn_y_la_preocupacin_de_Washington_y_ Pars> Consultado el 12 de noviembre de 2008.

Qiang, Z., Sino-African relations at a new stage of development, The Institute of Developing Economies, Japan External Trade Organization, Tokio, 2007. <www.ide.go.jp/Japanese/Publish/Report/pdf/2007_03_03_3_ zeng_eo.pdf $>$

Qinglian, H., "The Sino-African cooperation against human rights", China Rights Forum, núm. 1, 2007. <http://hrichina.org/public/contents/artic le?revision\%5fid $=45074$,item\%5fid $=34623>$

Ramo, J. C., Beijing Consensus, The Foreign Policy Center, Londres, 2004.

Rocha Pino, M. de J., "China en transformación: La doctrina del desarrollo pacífico”, Foro Internacional, octubre-diciembre, año XLVI, núm. 4, El Colegio de México, México, 2006, pp. 663-719.

Rocha, J., "China y los recursos naturales de África: Oportunidad para el desarrollo o profundización en la maldición de los recursos", África, la nueva frontera china. Boletin GovernÁsia, núm. 6, Casa Ásia, Barcelona, 2008. <http://www.casaasia.es/governasia/boletin/>

Sautman, B. V., "Friends and Interests: China's Distinctive Links with Africa", Working Paper, núm. 12, Centre on China's Transnational Relations, The Hong-Kong University of Science and Technology, Hong Kong, 2006, p. 40. 〈http://www.cctr.ust.hk/articles/pdf/WorkingPaper12.pdf>

Servant, J. C., "China's trade safari in Africa", Le Monde Diplomatique, mayo 2005.

Shelton, G., "China, Africa and Asia, advancing south-south co-operation", en A. Boron, y G. Lechini (eds.), Politics and social movements in an hegemonic world: Lessons from Africa, Asia and Latin America, Consejo Latinoamericano de Ciencias Sociales, Buenos Aires, junio, 2005, pp. 347-383.

Shinn, C., y J. Eisenman, "Dueling priorities for Beijing in the Horn of Africa", China Brief, A Journal of analysis and information, vol. V, núm. 21, 13 de octubre, The Jamestown Foundation, Washington, 2005, pp. 6-9. 
Sichor, Y., "Sudan: China's Outpost in Africa”, China Brief, A Journal of analysis and information, vol. V, núm. 21, 13 de octubre, The Jamestown Foundation, Washington, 2005, pp. 9-11.

Taylor, I., "China's foreign policy towards Africa in the 1990s", Journal of Modern African Studies, vol. 36, septiembre, 1998, pp. 443-460.

- - "Sino-African relations and the problem of human rights", African Affairs, núm.107, 2008, pp. 63-87.

Thompson, D., "China's soft power in Africa: From the "Beijing Consensus" to health diplomacy", China Brief, A Journal of analysis and information, vol. V, núm. 21, 13 de octubre, The Jamestown Foundation, Washington, 2005, pp. 1-4.

UnCTAD, Informe sobre las inversiones en el mundo, 2007, Naciones Unidas, Nueva York, 2007.

UNCTAD/FDI/TNC, World Investment Report 2006. FDI from Developing and Transition Economies: Implications for Development, ONU, Ginebra, 2007.

Van De Looy, J., “Africa and China: A strategic partnership?", ASC Working Paper, núm. 67, African Studies Centre, Leiden, Países Bajos, 2006.

Wang, C., y D. Flam, "Bridging the gap: Experiences and attitudes in SinoAfrican relations", China Rights Forum, núm. 2, 2007. <hrichina.org/ public/pdfs/crf.2.2007/crf-2007-2_sino-african.pdf>

Wang, J. Y., "What Drives China's Growing Role in Africa?", IMF Working Paper, núm. 7/211, Fondo Monetario Internacional, Washington, 2007.

Wang, J. Y., y A. Bio-Tchané, “África estrecha los lazos con China”, Finanzas y Desarrollo, marzo, 2008.

Wenping, H., "The balancing act of China's Africa policy", China Security, vol. 3, núm. 3, verano, World Security Institute, Washington, 2007, pp. 23-40.

Xinhuanet.com, "Comercio China-África superará 100,000 mdd en 2010", 6 de noviembre de 2006. <http://spanish.mofcom.gov.cn/aarticle/subject/ sinoafrica/lanmuxbyb/200611/20061103638962.html> Consultado el 15 de noviembre de 2007.

Yi, X., “Chinese foreign policy in transition: Understanding China's peaceful development", Journal of East Asian Foreign Affairs, vol. 14, núm.1, primavera, 2005.

Zafar, A., "The growing relationship between China and Sub-Saharan Africa: Macroeconomic, trade, investment, and aid links", The World Bank Research Observer, Washington, 2007. 